\title{
Animal Welfare, Market Power and Tangential Interests.
}

\author{
Daniel Parsons ${ }^{1}$
}

The history of social movements which attempt to bring previously marginalized issues to the forefront is replete with examples of conflict between cooperation, compromise and collaborating among actors whose interests and motivations only tangentially coincide on the one hand and a desire to work with people whose aims and beliefs fit (nearly) perfectly with one's own. Historical pathways are rarely straight-forward and are rarely formed by isolated sets of actors.

In Kamila Lis' Coalitions in the Jungle, the author traces a brief history of the meat processing industry in the United States from 1890 to present and the industry's impact on animal welfare. She places special emphasis on how advances and retreats in animal protection have come about often through cooperation with actors exogenous to the animal welfare movement.

For Lis, the history of the meat processing industry and levels of animal welfare is one of market concentration, de-concentration and re-concentration. The systematic abuse of animals has historically reached its zenith during periods of concentration; oligarchic market power in the meat processing industry is closely linked with negative externalities such as lax animal and human safety standards, poor labor conditions and the attendant accidents and animal abuse due to overwork and frustration. When this market power is coupled with coziness between the industry and the regulators who oversee it animal abuses routinely go unchecked. As such, Lis considers the concentration of the meat industry as the principal target for improving animal welfare and living standards. However, concentrated power rarely accedes to de-concentration willingly and de-concentrating power requires action across multiple pressure points. This in turn necessitates coordination among actors and groups whose interests align only tangentially.

The original concentration of the Meat Industry from the 1880 's until the 1930's. The widely acknowledged human and animal atrocities from this period are notably depicted in Upton Sinclair's The Jungle. These practices, particularly the human toll, came under fire from government Anti-Trust measures, such as the Packers and Stockyards Act (PSA), and from increased pressure from unions striving to improve

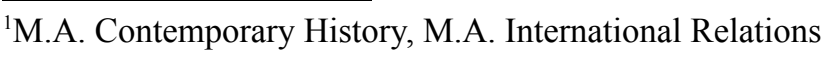


worker conditions within these plants. Lis sees the action by unions in promoting laborers' working condition as being vital to the promotion of animal welfare: "it was unions and not animal welfare groups that actually (albeit unintentionally) improved conditions for animals in slaughterhouses during the middle of the century." The common thread that tied together the human and animal mistreatment was the meat processing speed; observers had long noted that human and animal suffering was causally linked to increased processing speed. Union activists championed the decrease of processing speeds because "it not only improved the physical safety of the workers, but also simultaneously decreased their levels of frustration while on the job", benefits which decreased the prevalence of "inadvertent blunders" and "intentional animal abuses in the slaughterhouse" (p. 75). Hence, Lis attests that the very real improvements to animal treatment that accompanied the following period of market de-concentration came about as result of union activists fighting for better working conditions. This contention is not intended to diminish the work of animal welfare groups, but rather to show how actors with tangential interests and political voice can achieve material advances in animal welfare.

These increases in human and animal safety standards which accompanied the wave of de-concentration proved ephemeral with the introduction of Concentrated Animal Feeding Operations (CAFO's) in the 1960's, a renewed desire for meat consumption and the rise of the American fast food industry. These three factors mutually reinforced one another, and concentration within the meat industry rose again to fulfill the ever-expanding demand for meat products. The increased concentration was once again accompanied by a rise in abuse, animal deprivation and pain, and a reduction in animal welfare standards. Yet, just as in the past, when meat-packing workers conditions worsened, the new concentration of the animal industry has forced negative externalities over a broad swath of actors who could in turn be fruitful sources of collaboration to challenge the concentration of meat industry market power.

Lis focuses on one group of actors in particular, small animal producers, whose production capacities, measures and standards have all come under pressure or become subjugated to the rules of the meat-processing industry. Contracted meat purchases, imposed growing standards impossible to meet through natural growth processes, and distorted incentives for the agricultural cultivation of corn combine to tangentially align the interests of small farmers with those of the animal welfare movement, just as the interests of unions were partially aligned with animal welfare groups in the past. In Lis' opinion, this creates a window of opportunity through which material gains for animals can be obtained via cooperation with small animal producers, by combining the legal expertise of the animal welfare community with the 
untapped possible political, economic and moral ${ }^{2}$ strength of small producers to exploit current legal ambiguities in court decisions related to the PSA and fight the tide of re-concentration in the meat industry.

At its core, Lis' article is one that posits a question most social movements have encountered in their history: the inescapable tension between purity of mission and the possibility of realizing tangible gains through compromise. The ultimate goals of animal welfare activists can inevitably find tension with the goals of small animal producers, yet profound advances can be forged via cooperation while the window of opportunity is still open, though, as Lis contests, this avenue is one that has remained mostly unexplored. Given that negative externalities from the meat processing industry are being imposed on a wide variety of actors (small farmers, environmentalists, public health advocates, among others), this question of purity of mission versus tangible advances is one likely to come up again.

\footnotetext{
2" I have used the term moral here to suggest that many U.S. Consumers, including those outside the realm of animal welfare activists, may perceive the cause of small producers to be a morally just one, as an underdog David against a new Goliath.
} 